\title{
AVALIAÇÃO DA INFLUÊNCIA DO TEMPO DE DEPOSIÇÃO NA RESISTÊNCIA À CORROSÃO DE FERRAMENTAS DE AÇO REVESTIDAS COM NÍQUEL DUPLEX
}

\author{
Natasha Sidegum ' \\ Leonardo Felix Scheffel ' \\ Bruna Zorzanello ' \\ Fernando Dal Pont Morisso ' \\ Carlos Leonardo Pandolfo Carone ${ }^{\prime}$ \\ Cláudia Trindade Oliveira ${ }^{\prime}$ \\ Sandra Raquel Kunst' \\ Luciane Taís Führ'
}

\section{Resumo}

O revestimento de níquel duplex é utilizado para dar resistência à corrosão em ferramentas de aço. A proporção de níquel brilhante e níquel semi-brilhante na espessura do revestimento é parâmetro importante para seu desempenho, e varia principalmente com o tempo de deposição. Assim, o objetivo desse trabalho é avaliar a influência da espessura do revestimento de níquel duplex na resistência à corrosão de ferramentas de aço. Para tanto, foram realizados ensaios em bancada e estudo em planta industrial com alteração dos tempos de deposição. As camadas eletrodepositadas foram caracterizadas quanto à corrosão por meio de névoa salina, medição de espessura e diferença de potencial por step test e morfologia por microscopia eletrônica de varredura. $O$ melhor resultado de resistência à corrosão ocorreu com tempos de deposição de níquel semi-brilhante por 7 minutos e níquel brilhante por 3 minutos.

Palavras-chave: Eletrodeposição; Resistência à corrosão; Níquel; Espessura de camada.

\section{EVALUATION OF DEPOSITION TIME ON CORROSION RESISTANCE OF DUPLEX NICKEL PLATTED STEEL TOOLS}

\begin{abstract}
Duplex nickel coating is used to provide corrosion resistance in steel tools. Proportion of bright nickel and semi-bright nickel coating important for its performance, and varies mainly with the deposition time. Thus, the objective of this work is to evaluate the influence of the thickness of the duplex nickel coating on the corrosion resistance of steel tools. For that, a study was carried out in the laboratory and in an industrial plant with different deposition times. The duplex nickel layers were characterized for corrosion by means salt spray, thickness measurement and potential difference by step test and morphology by scanning electron microscopy. The best corrosion resistance result occurred with semi-bright nickel deposition times for 7 minutes and bright nickel for 3 minutes.
\end{abstract}

Keywords: Electrodeposition; Corrosion resistant; Nickel; Layer thickness.

\section{INTRODUÇAO}

Atualmente, a tecnologia de eletrodeposição de níquel tem sido amplamente desenvolvida para a produção eficiente de uma grande variedade de revestimentos. O uso generalizado do níquel na galvanoplastia reflete suas propriedades úteis como a resistência à corrosão. Por meio do processo corrosivo, o material metálico passa da forma metálica (menos estável) para a forma combinada (forma iônica) que é mais estável, resultando em deterioração, perda de propriedades, alterações estruturais, etc. Desta forma, a corrosão é um processo natural, mas indesejável. Contudo, os princípios da corrosão são usados em processos induzidos úteis, como a eletroerosão ou a eletrodeposição. $\mathrm{Na}$ eletrodeposição, uma camada metálica é depositada sobre uma superfície de metal base, utilizando-se uma célula

IInstituto de Ciências Criativas e Tecnológicas - ICCT, Universidade Feevale, Novo Hamburgo, RS, Brasil. E-mail: ctofeevale@gmail.com 
eletrolítica. Esta técnica permite que o metal depositado funcione como elemento de sacrifício, corroendo-se frente à ação natural do oxigênio e impedindo a oxidação do metal base [I]. Na indústria, dependendo das aplicações do material produzido, determina-se uma espessura de camada dos depósitos metálicos para atendimento da resistência à corrosão. Uma forma de se avaliar se o processo atende o especificado é proceder nas peças produzidas o ensaio de névoa salina $[2,3]$. Este ensaio é preferido frente à outras técnicas dento do ambiente industrial por ser de fácil manipulação e interpretação. Para tanto, o ensaio de névoa salina utiliza o mecanismo de corrosão em célula de concentração de oxigênio para acelerar a corrosão, para análise do desempenho em uma variedade de substratos e revestimentos [4]. Por sua vez, a eletrodeposição é tradicionalmente utilizada nas indústrias por ser um processo já consolidado e bem entendido. A espessura das camadas dos revestimentos obtidos no tratamento superficial depende principalmente do tempo de deposição e da densidade de corrente elétrica que flui de um eletrodo para o outro [5]. A espessura real em qualquer ponto da superfície eletrodepositada vai depender da densidade de corrente neste ponto e a densidade de corrente em qualquer ponto é determinada pela forma como a corrente é distribuída sobre a superfície. Em revestimentos de níquel, a distribuição é determinada por fatores geométricos: formato da peça, pela distância relativa da peça em relação ao ânodo e a forma como as peças são posicionadas nos suportes dos tanques. A densidade de corrente será maior em áreas e proeminências da peça que se encontram mais próximas ao ânodo e isso ocorre devido à menor resistência ao fluxo de corrente (áreas de alta densidade de corrente-ADC). Inversamente, a corrente será mais baixa nas regiões sombreadas ou afastadas do ânodo devido à maior resistência ao fluxo de corrente (áreas de baixa densidade de corrente-BDC). Estas variações na densidade resultam em camadas mais espessas em regiões que se encontram mais próximas ao ânodo em relação aquelas que estão mais afastadas do ânodo [6].

O sistema biníquel (também conhecido por duplex) é composto pelos processos de níquel semi-brilhante e níquel brilhante. Banhos de níquel semi-brilhante apresentam em sua composição sulfato de níquel, cloreto de níquel, ácido bórico e agentes de nivelamento [7]. Estes agentes, em sua maioria cumarina, têm sido substituídos por outros compostos orgânicos [8], sendo os acetilênicos os mais utilizados. O depósito de níquel semi-brilhante é parte essencial nos revestimentos multicamadas por apresentar boa ductilidade. Esta característica é importante em aplicações onde revestimentos multicamadas são forçados em serviço. O níquel brilhante, por sua vez, é amplamente usado em aplicações automotivas e, principalmente, para atingir brilho em ferragens, tais como ferramentas manuais. Os banhos de níquel brilhante usam combinações de agentes orgânicos, como o ácido sulfônico aromático, para alcançar um depósito com característica brilhante [9]. O revestimento de níquel brilhante é obtido a partir de eletrólitos semelhantes ao do níquel semi-brilhante, mas neste caso a solução contém um ou mais aditivos orgânicos contendo enxofre que são incorporados no revestimento e levam a uma estrutura diferente daquela observada no semi-brilhante. A codeposição de enxofre altera a tensão interna intrínseca de tração e compressão do níquel eletrodepositado favorecendo o aumento da sua dureza [10]. Os revestimentos formados pelo sistema biníquel são geralmente constituídos por uma camada relativamente espessa de níquel semi-brilhante ( 60 a $75 \%$ da espessura total de níquel) seguido por um revestimento de níquel brilhante mais fino ( 25 a $40 \%$ da espessura total de níquel). $O$ níquel semi-brilhante difere do níquel brilhante na medida em que não possui enxofre co-depositado e apresenta estrutura de grãos em formato colunar, enquanto que o níquel brilhante possui enxofre em sua composição e estruturas de grãos em formato lamelar [6]. No revestimento de camadas de níquel duplex, devido à composição da superfície, a camada de níquel brilhante é anódica em relação a camada de níquel semi-brilhante e, portanto, a camada de níquel brilhante corrói por sacrifício. Em função desta característica, durante o processo de corrosão, a penetração na interface das camadas de níquel brilhante/semi-brilhante é retardada e a corrosão procede principalmente lateralmente na camada de níquel brilhante [I I]. Os melhores resultados para resistência à corrosão são obtidos quando a camada de níquel semi-brilhante constitui $2 / 3$ da camada total de níquel $[7,12]$.

Desta forma, o presente estudo tem por objetivo avaliar a faixa de composição de espessura de níquel duplex quanto à resistência à corrosão e morfologia, obtidas através de variações no tempo de deposição de níquel semi brilhante e níquel brilhante. Um comparativo entre estudo em bancada e em escala industrial também foi realizado.

\section{MATERIAIS E MÉTODOS}

Para a realização deste trabalho, foi proposto o estudo comparativo entre três condições de variação de tempo de deposição de níquel semi-brilhante e brilhante em ferramentas manuais, identificadas como testes. Os parâmetros industriais utilizados atualmente caracterizam o teste I, em que é aplicado um revestimento de níquel duplex que compreende duas camadas: níquel semi-brilhante e níquel brilhante. Industrialmente estas duas camadas são depositadas com mesmo tempo de deposição, e com isso, a camada de níquel duplex compõem-se de $50 \%$ de níquel semi-brilhante e de $50 \%$ de níquel brilhante. No entanto, a literatura recomenda uma proporção de espessura de camada para o revestimento níquel duplex de 60 a $75 \%$ de níquel semi-brilhante e 25 a $40 \%$ de níquel brilhante. Portanto, para obtenção de uma máxima resistência à corrosão, dois testes foram propostos com respeito a essas proporções, em comparação com os parâmetros já adotados. Os testes foram realizados em escala de bancada utilizando amostras na forma de chapas de aço carbono de $100 \times 70 \times 0,75 \mathrm{~mm}$; e em escala de produção industrial 
utilizando uma peça de geometria mediana, cuja área era I,76 dm²/peça, já inspecionada e liberada para o processo de galvanoplastia. Os testes em escala industrial foram realizados para verificar a repetibilidade de resultados dos testes em bancada quando em ambiente controlado com menor precisão do que em laboratório.

O eletrólito utilizado nos testes de bancada foi coletado em amostras de 20 litros dos banhos de níquel semi-brilhante e níquel brilhante diretamente da linha de produção da empresa. Análises volumétricas de argentimetria, complexometria e volumetria de neutralização foram feitas para verificar a composição dos eletrólitos (Tabela I). $\mathrm{O} \mathrm{pH}$ foi medido em um pHmetro de bancada, marca Digimed, modelo DM-22.

Nas eletrodeposições foram utilizados ânodos de níquel tipo pellets, armazenados em cestos de titânio. As amostras de aço foram desengraxadas com o mesmo processo químico usado na linha de produção. Para aplicação de corrente foi utilizado um retificador de alta frequência Holiverbrass AF00. As Tabelas 2 e 3 apresentam os parâmetros de processo utilizados em escala de bancada e em escala produtiva.

Após a eletrodeposição foram determinadas as espessuras das camadas de níquel semi-brilhante e níquel brilhante por meio do Step Test, com uso de um colouscopio modelo Couloscope CMS2 Step, conforme método proposto pela ASTM B-764 [13]. Os ensaios de resistência à corrosão por névoa salina neutra foram realizados de acordo com as normas NBR 8094 [14] e ASTM B-I I7 [15], em um ciclo total de $24 \mathrm{~h}$ de exposição. Para critério de avaliação da resistência à corrosão foi usada a Tabela 4.
A caracterização morfológica dos revestimentos foi realizada por microscopia eletrônica de varredura em seção transversal, nas amostras previamente atacadas com solução de ácido acético e ácido nítrico I: I por 5 segundos. As amostras foram metalizadas com um filme fino de ouro e o equipamento utilizado foi um Microscópio Eletrônico de Varredura modeloJEOL-JSM 65IOCV com resolução de $129 \mathrm{eV}$, disponível no Laboratório de Estudos Avançados em Materiais da Universidade Feevale.

\section{RESULTADOS}

\section{I Espessura da Camada}

As Figuras I e 2 apresentam os resultados de espessura das camadas obtidas por Step Test, e a Tabela 5 mostra as diferenças de potencial (ddp) neste ensaio. De acordo com as Figuras I e 2, verifica-se que há uma variação de espessura ao longo das camadas eletrodepositadas nas regiões de alta e baixa densidade de corrente. Isso já era esperado, já que há relação entre a distribuição de corrente e a espessura de camada. O fluxo de corrente para peças (ou parte de peças) que ficam mais distantes do ânodo é menor do que aquelas que ficam próximas. Ou seja, a densidade de corrente é menor nas áreas distantes (Baixa densidade de corrente-BDC) pois a corrente encontra mais resistência a sua passagem nesses pontos do que nas posições próximas do ânodo (regiões de Alta densidade de corrente - ADC). Essa variação foi observada devido à variação de desvio padrão. No entanto, no Teste $3 \mathrm{em}$

Tabela I. Concentração dos banhos de níquel

\begin{tabular}{ccc}
\hline Produto & $\begin{array}{c}\text { Concentração dos produtos no eletrólito de } \\
\text { Níquel Semi-Brilhante }\end{array}$ & $\begin{array}{c}\text { Concentração dos produtos no eletrólito } \\
\text { de Níquel Brilhante }\end{array}$ \\
\hline Cloreto de níquel & $50 \mathrm{~g} / \mathrm{L}$ & $70 \mathrm{~g} / \mathrm{L}$ \\
Sulfato de níquel & $270 \mathrm{~g} / \mathrm{L}$ & $280 \mathrm{~g} / \mathrm{L}$ \\
Ácido bórico & $42,5 \mathrm{~g} / \mathrm{L}$ & $42,5 \mathrm{~g} / \mathrm{L}$ \\
$\mathrm{pH}$ & 3,6 & 4,2 \\
\hline
\end{tabular}

Tabela 2. Parâmetros de processo utilizados na eletrodeposição em escala de bancada (processo individual para cada amostra)

\begin{tabular}{rccc}
\hline Parâmetros & Teste I & Teste 2 & Teste 3 \\
\hline Tempo de Níquel Semi-Brilhante & $5 \mathrm{~min}$ & $6 \mathrm{~min}$ & $7 \mathrm{~min}$ \\
Tempo de Níquel Brilhante & $5 \mathrm{~min}$ & $4 \mathrm{~min}$ & $3 \mathrm{~min}$ \\
Corrente aplicada & $8,4 \mathrm{~A}$ & $8,4 \mathrm{~A}$ & $8,4 \mathrm{~A}$ \\
Área de depósito & $1,4 \mathrm{dm}^{2}$ & $1,4 \mathrm{dm}^{2}$ & $1,4 \mathrm{dm}^{2}$ \\
Temperatura dos banhos de níquel & $55^{\circ} \mathrm{C}$ & $55^{\circ} \mathrm{C}$ & $55^{\circ} \mathrm{C}$ \\
\hline
\end{tabular}

Tabela 3. Parâmetros de processo utilizados na eletrodeposição na linha de produção (lotes de 120 peças)

\begin{tabular}{cccc}
\hline Parâmetros & Teste I & Teste 2 & Teste 3 \\
\hline Tempo de Níquel Semi-Brilhante & $5 \mathrm{~min}$ & $6 \mathrm{~min}$ & $7 \mathrm{~min}$ \\
Tempo de Níquel Brilhante & $5 \mathrm{~min}$ & $4 \mathrm{~min}$ & $3 \mathrm{~min}$ \\
Corrente aplicada & $1267,2 \mathrm{~A}$ & $1267,2 \mathrm{~A}$ & $1267,2 \mathrm{~A}$ \\
Área de depósito & $211,2 \mathrm{dm}^{2}$ & $211,2 \mathrm{dm}^{2}$ & $211.2 \mathrm{dm}^{2}$ \\
Temperatura dos banhos de níquel & $55^{\circ} \mathrm{C}$ & $55^{\circ} \mathrm{C}$ & $55^{\circ} \mathrm{C}$ \\
\hline
\end{tabular}


Tabela 4. Classificação do nível de corrosão [16]

\begin{tabular}{cc}
\hline Avaliação & Significado \\
\hline F0 & Isento de corrosão vermelha \\
FI & Pontos de corrosão vermelha em áreas localizadas \\
F2 & Pontos de corrosão vermelha em geral \\
F3 & Áreas localizadas de corrosão vermelha \\
F4 & Parcial: pontos e áreas de corrosão vermelha \\
F5 & Corrosão vermelha total \\
\hline
\end{tabular}

Tabela 5. Resultados de diferença de potencial entre as camadas de níquel semi-brilhante e brilhante por Step Test

\begin{tabular}{cccc}
\hline \multirow{2}{*}{ Teste } & Área da & \multicolumn{2}{c}{ ddp $(\mathbf{m V})$} \\
\cline { 3 - 4 } & amostra & Bancada & Produção \\
\hline I & BDC & 137 & 133 \\
& ADC & 146 & 136 \\
2 & BDC & 132 & 122 \\
& ADC & 139 & 126 \\
3 & BDC & 126 & 127 \\
& ADC & 157 & 130 \\
\hline
\end{tabular}

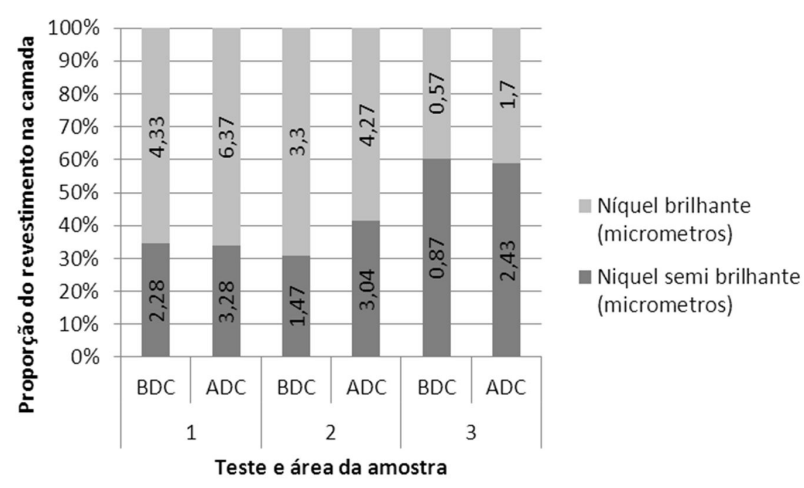

Figura I. Espessuras das camadas de níquel obtidas em escala de bancada; $A D C=$ alta densidade de corrente (entre I e $3 \mathrm{~cm}$ de distância do ânodo); $\mathrm{BDC}=$ baixa densidade de corrente (entre 8 e $10 \mathrm{~cm}$ de distância do ânodo).

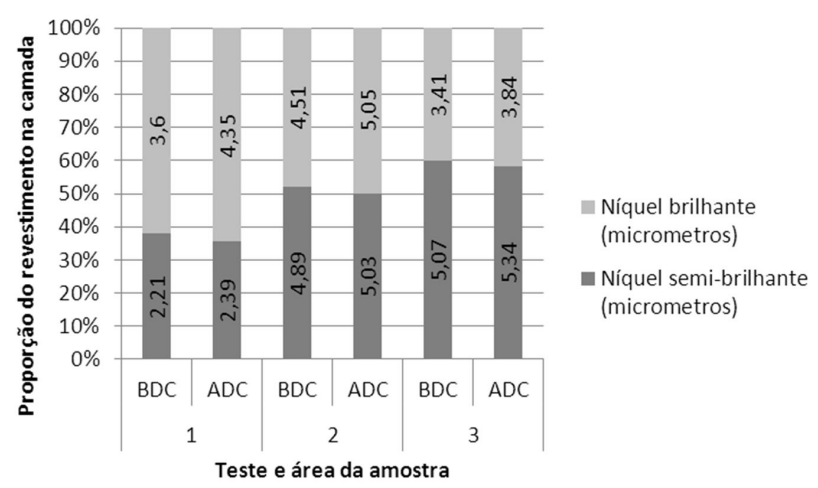

Figura 2. Espessuras da camada de níquel obtidas em escala de produção; $A D C=$ alta densidade de corrente (entre $\mathrm{l}$ e $3 \mathrm{~cm}$ de distância do ânodo); $\mathrm{BDC}=$ baixa densidade de corrente (entre 8 e $10 \mathrm{~cm}$ de distância do ânodo) escala de bancada (região BDC) e nos testes I e 2 da escala produtiva (região de BDC), o desvio padrão foi menor do que I micrômetro tanto na camada de níquel semi-brilhante quanto na camada de níquel brilhante. Esta variação era esperada, já que, conforme Di Bari [17], a camada eletrodepositada depende de uma série de fatores geométricos, entre eles a posição da peça em relação aos ânodos.

Contudo, a grande variação dos resultados entre as amostras do mesmo teste pode estar relacionada com a temperatura da solução ou o grau de agitação da mesma $[18,19]$ uma vez que no laboratório os banhos foram aquecidos até a temperatura de trabalho e não foi possível o controle da temperatura. Outra possível interferência pode estar associada ao mecanismo de agitação adotado, que pode não ser o adequado para o teste proposto.

Ao se comparar os tempos de deposição de cada banho de níquel e as espessuras de camada em cada teste, observa-se que nenhuma das amostras apresentou uma relação de $50 \%$, $60 \%$ e $70 \%$ para as camadas de níquel semi-brilhante e de $50 \%$, $40 \%$ e $30 \%$ para as camadas de níquel brilhante. Estes resultados aleatórios mostram que houve pouca repetitividade nos ensaios em escala de bancada. Resultados semelhantes foram obtidos em laboratório por Martins [20], associados à baixa eficiência catódica. No presente estudo, essa baixa eficiência catódica possivelmente foi influenciada pela agitação não adequada para o volume de banho utilizado, o que gerou distribuição não uniforme da densidade de corrente para as amostras.

Observando a Figura 2, comparando-se os tempos de deposição de cada banho de níquel e as espessuras de camada em cada teste, observa-se que no teste I, as amostras apresentaram uma relação média de 37\% e 63\% para as camadas de níquel eletrodepositadas. No teste 2 , as amostras apresentaram uma relação média de $51 \%$ e $49 \%$. Já no teste 3 , as amostras apresentaram uma relação média de $59 \%$ e $41 \%$ para cada camada de níquel. Reis [2। ] menciona que espessuras de camada uniformes significam que os banhos apresentam bom poder de penetração.

Liu et al. [19] ao estudar parâmetros de polimento eletrolítico para melhorar o desempenho do revestimento de níquel sobre aço verificou que, ao alterar a densidade de corrente, o tempo e a temperatura, a camada mais espessa de níquel foi obtida quando as amostras permaneceram mais tempo no eletrólito com passagem de corrente. Da mesma forma, pode-se observar que, nos testes em escala produtiva, a proporção média de níquel semi-brilhante aumentou com maior tempo de eletrodeposição de níquel em cada situação e a proporção média de níquel brilhante diminuiu para cada teste, já que os tempos neste banho foram menores. Os resultados de diferença de potencial (ddp) por Step Test, Tabela 4, mostram que todas as amostras, por apresentarem ddp acima de $100 \mathrm{mV}$, estão de acordo com o valor recomendado para garantia de uma boa resistência à corrosão, que é de 100 a $200 \mathrm{mV}$ para camadas de níquel duplex $[7,12]$. 
Tabela 6. Resultados do ensaio de névoa salina neutra

\begin{tabular}{|c|c|c|c|c|c|}
\hline Escala & Teste & Amostra & $4 h$ & $10 \mathrm{~h}$ & $24 \mathrm{~h}$ \\
\hline \multirow[t]{9}{*}{ Bancada } & 1 & I & $\mathrm{FI}$ & $\mathrm{FI}$ & $\mathrm{FI}$ \\
\hline & & 2 & $\mathrm{~F} 2$ & $\mathrm{~F} 2$ & $\mathrm{~F} 2$ \\
\hline & & 3 & $\mathrm{~F} 2$ & $\mathrm{~F} 2$ & $\mathrm{~F} 2$ \\
\hline & 2 & I & F0 & $\mathrm{FI}$ & $\mathrm{FI}$ \\
\hline & & 2 & $\mathrm{FI}$ & $\mathrm{FI}$ & $\mathrm{F} 2$ \\
\hline & & 3 & F0 & $\mathrm{F} 2$ & $\mathrm{~F} 2$ \\
\hline & 3 & I & $\mathrm{FI}$ & $\mathrm{FI}$ & $\mathrm{F} 2$ \\
\hline & & 2 & $\mathrm{~F} 2$ & $\mathrm{~F} 2$ & $\mathrm{~F} 2$ \\
\hline & & 3 & F0 & F0 & $\mathrm{FI}$ \\
\hline \multirow[t]{9}{*}{ De produção } & I & I & $\mathrm{FI}$ & $\mathrm{F} 2$ & $\mathrm{~F} 2$ \\
\hline & & 2 & $\mathrm{FI}$ & $\mathrm{F} 2$ & $\mathrm{~F} 2$ \\
\hline & & 3 & $\mathrm{FI}$ & $\mathrm{F} 2$ & $\mathrm{~F} 2$ \\
\hline & 2 & I & $\mathrm{FI}$ & $\mathrm{FI}$ & $\mathrm{F} 2$ \\
\hline & & 2 & $\mathrm{FI}$ & $\mathrm{FI}$ & $\mathrm{F} 2$ \\
\hline & & 3 & $\mathrm{FI}$ & $\mathrm{FI}$ & $\mathrm{F} 2$ \\
\hline & 3 & I & F0 & $\mathrm{FI}$ & $\mathrm{F} 2$ \\
\hline & & 2 & F0 & $\mathrm{FI}$ & $\mathrm{F} 2$ \\
\hline & & 3 & F0 & $\mathrm{FI}$ & $\mathrm{F} 2$ \\
\hline
\end{tabular}

\subsection{Resistência a Corrosão por Névoa Salina das Camadas Eletrodepositadas}

Os resultados de resistência à corrosão por névoa salina neutra, Tabela 6, mostram que as amostras em escala de bancada não apresentaram uniformidade nos resultados. Millen e Silva [7] e Yli-Pentti [12] afirmam que os melhores resultados para resistência à corrosão são obtidos quando a camada de níquel semi-brilhante constitui $2 / 3$ (ou cerca de $66 \%$ ) da camada total de níquel e, portanto, faz-se necessária a avaliação em conjunto da espessura das camadas de níquel com os resultados do ensaio de névoa salina.

Como visto nas Figuras I e 2, nenhuma das amostras avaliadas obteve percentual de $66 \%$ de espessura de camada de níquel semi-brilhante. Este fato, por consequência, influenciou diretamente na resistência à corrosão. As amostras em escala produtiva apresentaram uma coerência nos resultados do ensaio de névoa salina, conforme observado na Tabela 6. Em 4 horas de ensaio, as amostras dos testes I e 2 apresentaram comportamento semelhante, constatando-se somente a presença de pontos de corrosão vermelha em áreas localizadas, enquanto que, no teste 3 , as amostras não apresentaram qualquer incidência de corrosão vermelha. Em 10 horas de ensaio, as amostras do teste I evoluíram o processo de corrosão apresentando corrosão vermelha em geral. As amostras do teste 2, em 10 horas de ensaio, permaneceram na mesma condição observada em 4 horas e as amostras do teste 3 apresentaram pontos de corrosão vermelha em áreas localizadas. Em 24 horas, para todos os testes, as amostras apresentaram pontos de corrosão vermelha em geral. De certa forma, com estes resultados, observa-se que o aumento na espessura de camada de níquel semi-brilhante aumenta a resistência a corrosão.
No entanto, esta melhora foi significativa somente até as primeiras 10 horas de ensaio.

Song et al. [22] obtiveram resultados semelhantes ao estudarem revestimentos multicamadas de níquel, e concluíram que a camada mais externa de níquel era anódica em relação à camada de níquel intermediária e, portanto, a camada externa corroeu por sacrifício. Com isso, os melhores resultados de resistência à corrosão foram obtidos quando a camada de níquel intermediária era mais espessa que a camada externa. Acredita-se que um mecanismo semelhante ocorreu nas amostras do presente estudo, já que os resultados de Step Test mostraram ddp entre 100 e 200 mV, positivo, evidenciando que a camada externa de níquel brilhante é anódica em relação à camada de níquel semi- brilhante.

\subsection{Morfologia das Camadas Eletrodepositadas}

A Figura 3 mostra as micrografias de seção transversal para o teste 3, identificado com melhor desempenho nos ensaios anteriores. Observa-se a formação da camada de revestimento de níquel sobre o substrato de aço.

A Figura 4 apresenta análise de EDS da amostra de produção (peça), na alta densidade de corrente, como forma de verificar a composição química de cada região identificada.

$\mathrm{Na}$ Figura 4, verifica-se que o ponto I, localizado na região da camada eletrodepositada, apresenta predominantemente níquel em sua composição. Da mesma forma, o ponto 3, localizado na matriz de aço, apresenta ferro como elemento predominante. A presença de oxigênio nos pontos I e 3 possivelmente ocorre por conta da preparação metalográfica, pelo lixamento/polimento e ataque químico. O ponto 2 é o único que apresenta carbono, o que era esperado, já que a resina de embutimento é de polimérica. 

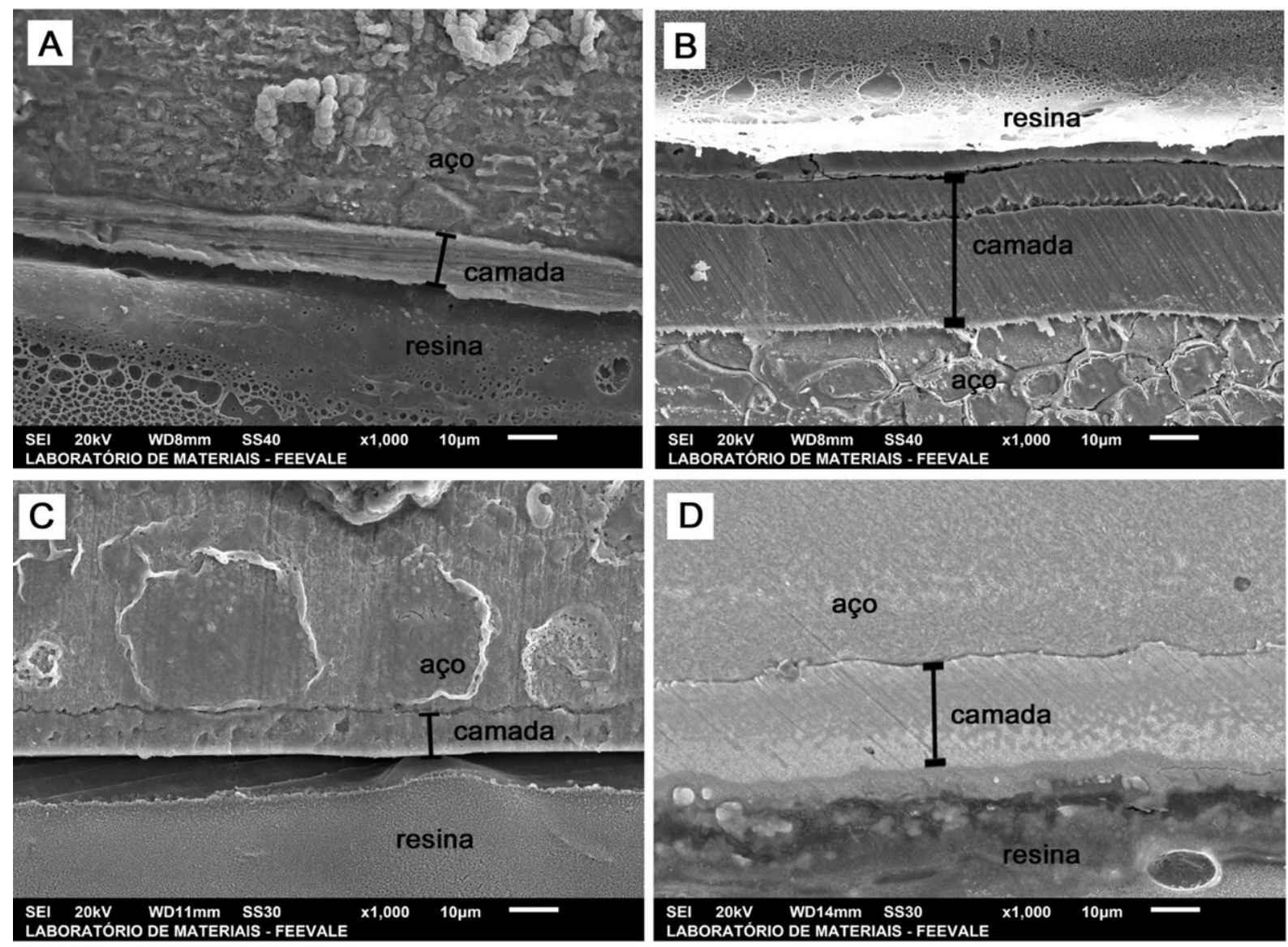

Figura 3. Micrografias de seção transversal do teste 3: chapa de aço $(A)$ região $B D C$, (B) região $A D C$, peça $(C)$ região $B D C$ e (D) região $A D C$. Sendo que $B D C=$ baixa densidade de corrente e $A D C=$ alta densidade de corrente.

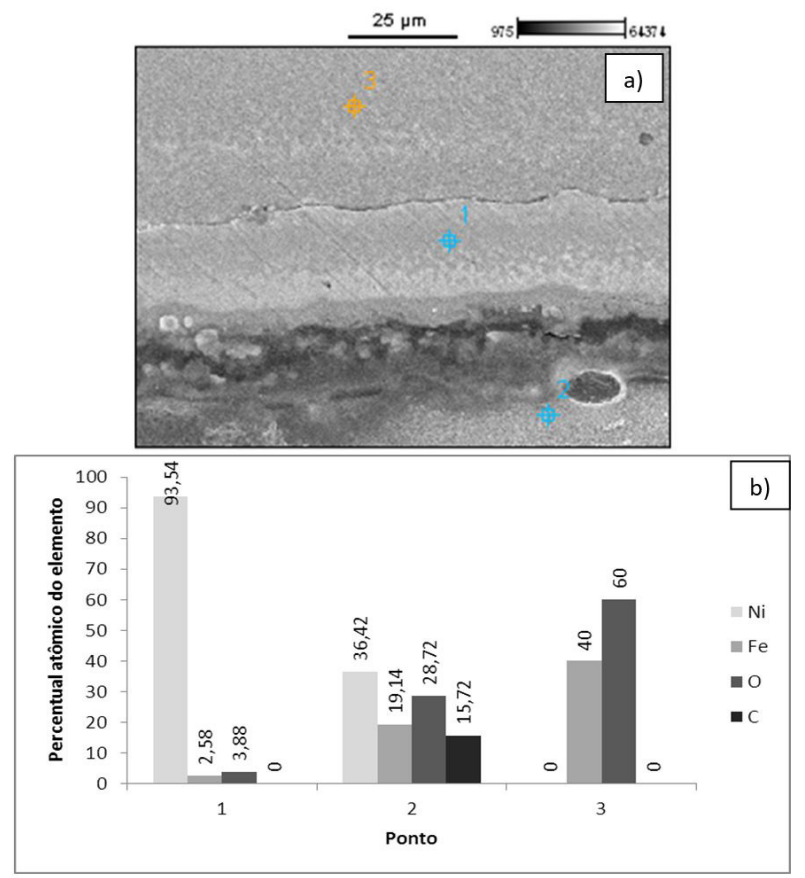

Figura 4. EDS de seção transversal do teste 3, peça região ADC: (a) pontos verificados; (b) percentual atômico médio da composição química dos pontos.

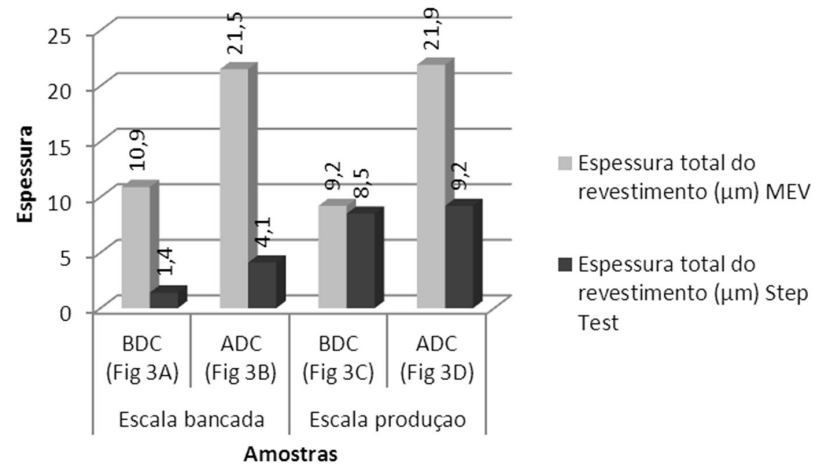

Figura 5.Espessura total da camada de níquel medidas com MEV no teste 3. Sendo que $A D C=$ alta densidade de corrente (entre 1 e $3 \mathrm{~cm}$ de distância do ânodo); $\mathrm{BDC}=$ baixa densidade de corrente (entre 8 e $10 \mathrm{~cm}$ de distância do ânodo).

A presença de níquel e ferro se deve possivelmente ao arraste desses elementos durante a preparação metalográfica.

A partir das micrografias, foi também determinada a espessura do revestimento total de níquel e os resultados foram plotados na Figura 5 . As espessuras de camada obtidas por MEV (Figuras 3 e 5) mostram que as amostras em escala de bancada e em escala produtiva apresentam coerência de 
resultados, sendo muito semelhantes. Contudo, se comparado o resultado de espessura de camada obtida ao MEV com as espessuras encontradas em Step Test, nota-se uma grande diferença. Pode-se correlaciona-la à heterogeneidade das amostras, pois não foram analisados exatamente nos mesmos pontos nos dois testes para cada região (BDC e ADC) das amostras em estudo. Esta significativa diferença pode estar relacionada com o fato da superfície do metal base ser bastante porosa e rugosa, gerando variação na deposição.

De acordo com Bradaschia [23], a morfologia do metal base possui estreita relação com a estrutura do depósito subsequente e irregularidades no metal base influenciam a espessura tanto em depósitos finos quanto espessos, podendo em determinados casos acentuar-se com a espessura. Como a análise por Step Test é pontual em relação à avaliação ao MEV, que abrande uma região da peça, a análise ao MEV parece ser mais coerente com a real situação analisada.

Contudo, em ambas as regiões de alta densidade de corrente nas Figuras 3B e 3D, observa-se que ocorreu uma formação de núcleos com velocidade maior que de desenvolvimento de cristais [23], uma vez que a descarga de íons se dá preferencialmente na extremidade da peça, onde a diferença de potencial entre eletrodo-solução é maior. Desta forma, é possível visualizar as interfaces das camadas de níquel, porém não é possível a identificação das estruturas relativas a cada uma.

$\mathrm{Na}$ Figura 5 é apresentada a espessura total da camada de níquel medidas com MEV no teste 3. Avaliando-se a Figura 5 , pode-se comparar a Figura $3 \mathrm{~B}$, onde é bem visível a interface de níquel semi-brilhante e níquel brilhante, e a Figura 3D, onde observam-se duas estruturas diferentes, porém não há nitidez entre estas, pode-se relacionar as alterações de tempo de deposição com o favorecimento no aumento da velocidade de formação dos núcleos em relação à velocidade de desenvolvimento dos cristais, o que favorece uma formação das camadas de níquel mais regulares e com granulação mais fina. No teste 3, esperava-se uma espessura maior de níquel semi-brilhante em relação à camada de níquel brilhante, uma vez que o tempo de depósito daquele foi maior. De fato, na Figura 3B, foi possível medir a espessura da camada de níquel semi-brilhante (aproximadamente I 4,5 micrometros), o que representa $63 \%$ do revestimento total. Esse valor é muito próximo ao estimado pelo tempo de deposição, cuja proporção esperada para a espessura de camada de níquel semi-brilhante era de $70 \%$.

\section{CONCLUSÃO}

A partir da discussão e análise dos resultados, observa-se que o tempo de deposição para ambas as camadas de níquel foi proporcional à espessura de camada obtida. $O$ aumento na espessura de camada de níquel semi-brilhante aumentou também a resistência à corrosão, mas esta melhora é significativa somente até as primeiras 10 horas de ensaio de névoa salina neutra. Os melhores resultados para a resistência à corrosão foram obtidos quando a camada de níquel semi-brilhante é mais espessa que a camada de níquel brilhante. Por fim, verifica-se que a melhor proporção entre o tempo de deposição de níquel semi-brilhante e o tempo de deposição de níquel brilhante para aumentar a resistência à corrosão em ferramentas de aço foi obtida no teste 3 , com deposição por 7 minutos de níquel semi-brilhante e por 3 minutos de níquel brilhante.

\section{REFERÊNCIAS}

I Gentil V. Corrosão. 6. ed. Rio de Janeiro: LTC; 20II. 360 p.

2 Pathak SS, Blanton MD, Mendon SK, Rawlins JW. Investigation on dual corrosion performance of magnesiumrich primer for aluminum alloys under salt spray test (ASTM B I 17) and natural exposure. Corrosion Science. 2010;52(4): I453-1463. http://dx.doi.org/10.1016/j.corsci.2009.1I.032.

3 Xu C, Du L, Yang B, Zhang W. Study on salt spray corrosion of Ni-graphite abradable coating with 80Ni20Al and $96 \mathrm{NiCr}-4 \mathrm{Al}$ as bonding layers. Surface and Coatings Technology. 20I I;205(I7-18):4I54-416I. http://dx.doi. org/10.1016/j.surfcoat.2011.03.007.

4 Blakeley A. Entendendo a corrosão em ensaio de névoa salina neutra: salt spray. Revista Tratamento de Superfície. 2016;33(I84): I.

5 Jurandi NA Jr. Obtenção e caracterização de filmes de $\mathrm{Ni}$ e tricamadas de Ni/Cu/Ni produzidos por eletrodeposição [dissertação]. Recife: Programa de Pós-graduação em Ciência de Materiais, Universidade Federal de Pernambuco; 2015.

6 Rose I, Whittington C. Nickel plating handbook. Brussels: Nickel Institute; 20I3. 80 p.

7 Millen W Jr, Silva MA. Curso de Galvanoplastia: banhos para a eletrodeposição de níquel. São Paulo: Associação Brasileira de Tratamento de Superfície; 2010. 8 p.

8 Schmitz EPS, Quinaia SP, Garcia JR, Andrade CK, Lopes MC. Influence of commercial organic additives on the nickel electroplating. International Journal of Electrochemical Science. 2016; I I (I):983-997. 
Sidegum et al.

9 Sadiku-Agboola O, Sadiku ER, Ojo OI, Akanji OL, Biotidara OF. Influence of operation parameters on metal deposition in bright nickel-plating process. Portugaliae Electrochimica Acta. 20 I I;29(2):9 I-I00. http://dx.doi. org/l0.4I52/pea.20I I0209I.

10 Imaz N, García-Lecína E, Díez JA. Corrosion properties of double layer nickel coatings obtained by pulse plating techniques. Transactions of The Imf. 20 I0;88(5):256-26I. http://dx.doi.org/I0. I I79/0020296 I0X I 279 I98 I 507767.

I I Wood W. Metals handbook: surface cleaning, finishing, and coating. 9th ed. Metals Park: American Society for Metals; 1982. 715 p. vol. 5.

12 Yli-Pentti A. Electroplating and electroless plating. In: Yli-Pentti A. Comprehensive materials processing. 4th ed. Vantaa: Elsiever; 20I4. Chap. 4.II, p. 277-306.

13 American Society for Testing and Materials. ASTM B-764-04(20I4): standard test method for simultaneous thickness and electrode potential determination of individual layers in multilayer nickel deposit (STEP test). Pennsylvania: ASTM International; 2009.

14 Associação Brasileira de Normas Técnicas. ABNT NBR 8094: corrosão por exposição à névoa salina: método de ensaio. Rio de Janeiro: ABNT; 1983.

I5 American Society for Testing and Materials. ASTM B- I I - I I: standard practice for operating salt spray (fog) apparatus. Pennsylvania: ASTM International; $201 \mathrm{I}$.

I6 Associação Brasileira De Normas Técnicas. ABNT NBR 8754: corpos-de-prova revestidos e expostos a ambientes corrosivos: método de avaliação. Rio de Janeiro: ABNT; 1985.

17 Di Bari GA. Electrodeposition of nickel. In: Schlesinger M, Paunovic M, editors. Modern electroplating. 5th ed. Ontário: John Wiley \& Sons; 201 I. p. 79-II4..

I 8 Menezes MC. Galvanotécnica. Novo Hamburgo: Fundação Escola Técnica Liberato Salzano Vieira da Cunha; 2008. Apostila do Curso Técnico em Química.

19 Liu M, Meng Y, Zhao Y, Li F, Gong Y, Feng L. Electropolishing parameters optimization for enhanced performance of nickel coating electroplated on mild steel. Surface and Coatings Technology. 2016;286:285-292.

20 Martins DF. Estudo de banhos ácidos para substituição de banho alcalino cianídrico na eletrodeposição de zinco sobre pregos [dissertação[. Porto Alegre: Programa de Pós-graduação em Engenharia de Minas, Metalurgia e Materiais, Universidade Federal do Rio Grande do Sul; 2009.

2I Reis LG. Tecnologia aplicada a processos galvânicos. São Paulo: Senai-SP Editora; 20I 5. 324 p.

22 Song YW, Shan DY, Han EH. High corrosion resistance multilayer nickel coatings on AZ9ID magnesium alloys. Surface Engineering. 2007;23(5):329-333. http://dx.doi.org/ I 0. I I 79// 74329407X260528.

23 Bradaschia C, editor. Corrosão e tratamento superficial dos metais. São Paulo: ABM; 1 97I.

Recebido em: 7 Ago. 2019

Aceito em: 21 Out. 2019 